\title{
Thermomechanical fatigue crack growth in a cast polycrystalline superalloy
}

\author{
Johan J. Moverare ${ }^{1,2, a}$, Paraskevas Kontis ${ }^{3}$, Sten Johansson ${ }^{1}$, and Roger C. Reed ${ }^{3}$ \\ ${ }^{1}$ Engineering Materials, Dept. of Management and Engineering, Linköping University, 58183 Linköping, Sweden \\ 2 Siemens Industrial Turbomachinery AB, Materials Technology, 61283 Finspång, Sweden \\ ${ }^{3}$ Department of Engineering Science, University of Oxford, Parks Road, Oxford OX1 3PJ, UK
}

\begin{abstract}
Thermomechanical fatigue (TMF) crack growth testing has been performed on the polycrystalline superalloy IN792. All tests were conducted in mechanical strain control in the temperature range between 100 and $750{ }^{\circ} \mathrm{C}$. The influence of in-phase (IP) and out-of-phase (OP) TMF cycles was investigated as well as the influence of applying extended dwell times (up to 6 hours) at the maximum temperature. The crack growth rates were also evaluated based on linear elastic fracture mechanics and described as a function of the stress intensity factor $K_{I}$. Without dwell time at the maximum temperature, the crack growth rates are generally higher for the OP-TMF cycle compared to the IP-TMF cycle, when equivalent nominal strain ranges are compared. However, due to the fact that the tests were conducted in mechanical strain control, the stress response is very different for the IP and OP cycles. Also the crack closure level differs significantly between the cycle types. By taking the stress response into account and comparing the crack growth rates for equivalent effective stress intensity factor rages $\Delta K_{\text {eff }}$ defined as $K_{\max }-K_{\text {closure }}$, very similar crack growth rates were actually noticed independent of whether an IP or OP cycle were used. While the introduction of a 6 hour dwell time significantly increased the crack growth rates for the IP-TMF cycle, a decrease in crack growth rates versus $\Delta K_{\text {eff }}$ were actually seen for the OP-TMF cycle. The fracture behaviour during the different test conditions has been investigated using scanning electron microscopy.
\end{abstract}

\section{Introduction}

The nickel-base superalloy IN792 is a cast polycrystalline material which is widely used in industrial and aircraft turbines due to its high strength and excellent hot corrosion resistance. Often the material can be found in critical components such as turbine blades and vanes. Even though such components sometimes are made in single crystalline form, polycrystalline materials are very common due to lower costs and easier production route.

Gas turbine blades and vanes are subjected to rather complex stress and temperature cycles due to the temperature gradients that occur during engine start-up and shut-down or from temperature gradients within the component during steady-state operation. The accumulation of such stress and temperature cycles leads to the possibility of failure by thermomechanical fatigue (TMF), which must be avoided by appropriate design of the component and choice of operating conditions. The service life of many hot components is not fully restricted by the number of cycles to crack initiation since, especially close to stress concentrations, one has to also rely on stable and predictable crack propagation, which means that a certain amount of crack propagation is allowed before the component has to be replaced in service. However, such

\footnotetext{
${ }^{a}$ Corresponding author: johan.moverare@liu.se
}

damage tolerant approaches demand accurate predictions of the crack growth under the influence of simultaneous cycling of temperature and mechanical loads. Although methods have been developed to predict crack growth rates under isothermal conditions over a wide range of temperatures, frequencies and load ratios, as well as under sustained load dwell times, only very few published studies on crack propagation under TMF conditions are available, see reference [1] for further references. Furthermore, since the translation of isothermally obtained fatigue crack propagation data into a true thermomechanical fatigue context is questionable, the need for more experimental studies in this field is obvious.

It is common to consider two main types of idealised TMF cycles; (IP) in-phase TMF in which the material undergoes creep relaxation in tension at high temperature and plastic deformation in compression at low temperature, (OP) out-of-phase TMF in which the material undergoes creep relaxation in compression at high temperature and plastic deformation in tension at low temperature. In a previous work, the behaviour of IN792 during TMF of smooth specimens has been investigated [2]. It was found that the majority of the cracks were transgranular in OP TMF-test, while there was some tendency to intergranular crack growth in IP TMF tests at $750{ }^{\circ} \mathrm{C}$. Furthermore it is known from other alloys that the intergranular cracking behaviour in wrought fine grained

This is an Open Access article distributed under the terms of the Creative Commons Attribution License 4.0, which permits unrestricted use, distribution, and reproduction in any medium, provided the original work is properly cited. 


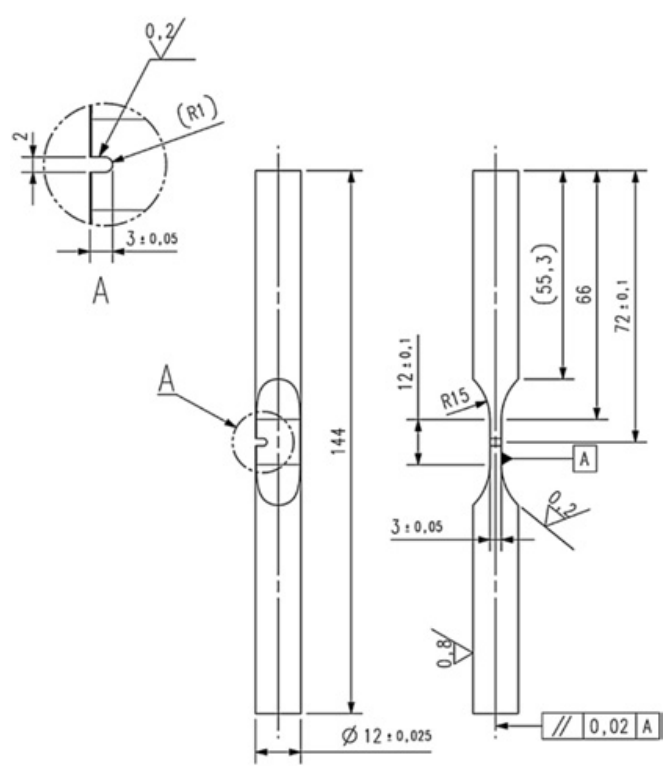

Figure 1. Specimen geometry.

material is enhanced by longer dwell times [1,3-5]. To what extent the coarse-grained cast material IN792 is sensitive to environmental assisted cracking during dwell times is to be determined in this study.

\section{Material and methods}

The chemical composition of the alloy IN792 investigated in this study is $\mathrm{Ni}-12.4 \mathrm{Cr}-8.9 \mathrm{Co}-1.8 \mathrm{Mo}-4.0 \mathrm{~W}-3.5 \mathrm{Al}-$ 4.0Ti-4.1Ta-0.08C-0.017B-0.019Zr (wt-\%). The test material was delivered by Howmet as cast round bars with a diameter of $20 \mathrm{~mm}$. After conventional casting (CC) the material was hot isostatically pressed (HIP) at $1195^{\circ} \mathrm{C}$ and $150 \mathrm{MPa}$ for 2 hours followed by solution heat treatment at $1121^{\circ} \mathrm{C}$ for 2 hours and then ageing at $850^{\circ} \mathrm{C}$ for 24 hours.

Single edge notched (SEN) type specimens were machined according to the drawing found in Fig. 1.

In-phase (IP) and out-of-phase thermomechanical fatigue cycling were conducted under mechanical strain control in the $100-750{ }^{\circ} \mathrm{C}$ temperature range using a MTS 810 servo-hydraulic thermo-mechanical fatigue machine. An extensometer with a 12-mm gauge length was symmetrically attached to the specimen over the notch. All tests were conducted in displacement control by prescribing the displacement of the extensometer gauge length. In this paper the displacement measured by the extensometer $(\Delta L)$ divide by the extensometer gauge length $\left(L_{0}\right)$ will be referred to as the nominal total strain $\left(\varepsilon_{\text {nom }}=\Delta L / L_{0}\right)$. To enable thermal cycling, induction heating has been used in combination with convection cooling from compressed air distributed onto the specimen by two cooling nozzles. The induction coil was designed in such a way that during heating, the main part of the heat input occurs at the shoulders of the specimen outside the gauge section of the specimen. Crack lengths were determined using the compliance method in a similar manner as outlined in ASTM E 647 for isothermal crack growth tests. This set-up is described in more detail in [1] where it was also found that one can achieve a temperature
Table 1. Test matrix.

\begin{tabular}{|c|c|c|c|}
\hline Test ID & Cycle type & Dwell & $\boldsymbol{\varepsilon}_{\text {nom }}$ \\
\hline 0201 & $\mathrm{IP}(\mathrm{R}=0)$ & $5 \mathrm{~min}$ & $0.4 \%$ \\
\hline 0202 & $\mathrm{IP}(\mathrm{R}=0)$ & $5 \mathrm{~min}$ & $0.6 \%$ \\
\hline 0203 & $\mathrm{IP}(\mathrm{R}=0)$ & $5 \mathrm{~min}$ & $0.4 \%$ \\
\hline 0204 & $\mathrm{IP}(\mathrm{R}=0)$ & $5 \mathrm{~min}$ & $0.5 \%$ \\
\hline 0205 & $\mathrm{OP}(\mathrm{R}=-\infty)$ & $5 \mathrm{~min}$ & $0.6 \%$ \\
\hline 0206 & $\mathrm{OP}(\mathrm{R}=-\infty)$ & $5 \mathrm{~min}$ & $0.7 \%$ \\
\hline 0207 & $\mathrm{IP}(\mathrm{R}=0)$ & 6 hours & $0.6 \%$ \\
\hline 0208 & $\mathrm{OP}(\mathrm{R}=-\infty)$ & 6 hours & $0.6 \%$ \\
\hline
\end{tabular}

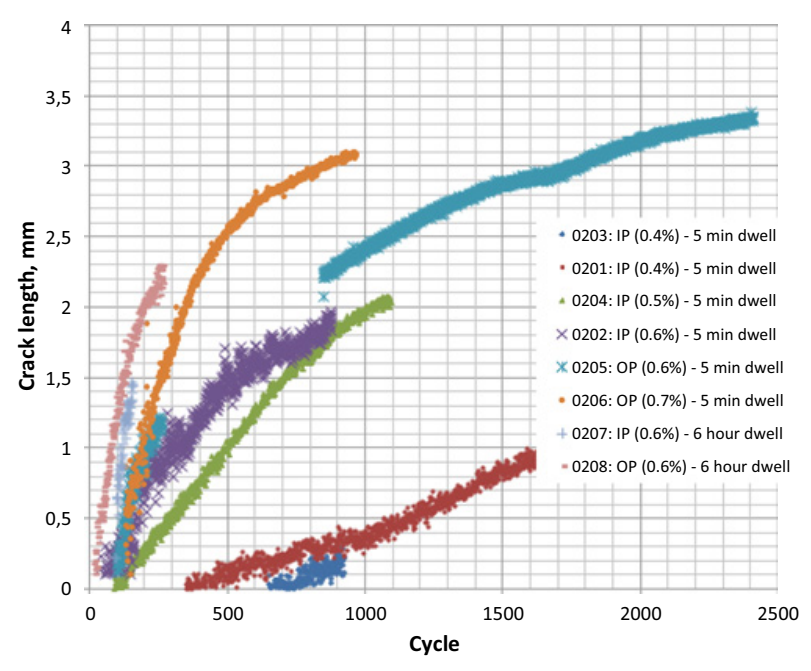

Figure 2. Crack length as a function of number of cycles.

gradient in the flat gauge section of the specimen, which is always less than $15^{\circ} \mathrm{C}$ if the heating and cooling rates are sufficiently low. As a consequence all tests have been conducted with a constant heating and cooling rate of $1{ }^{\circ} \mathrm{C} / \mathrm{s}$. In order to examine dwell time effects on TMF crack propagation, hold times of either 5 minutes or 6 hours were applied at the maximum temperature of the tests. The complete test matrix is summarised in Table 1.

Since the tests were conducted in mechanical strain control the stress imposed during the tests drop as the cracks become longer and the crack propagation rate slows down. Therefore most of the tests were interrupted before complete failure of the specimen. After the testing the specimens were sectioned parallel to the longitudinal axis and the crack appearance can then be studied in the cross sections. These samples were prepared by the usual metallographic procedures (grinding and mechanical polishing) and analysed using scanning electron microscopy (SEM) and electron backscatter diffraction (EBSD).

\section{Results and discussions}

\subsection{Crack growth rates}

The crack length as a function of cycle can be found in Fig. 2. As can be seen crack initiation occurred rather early in all tests and a significant amount of cycles were spent on crack propagation. For most tests the crack propagation rate decreased with increasing crack length, especially after that the crack reached a length of $2 \mathrm{~mm}$. This is 


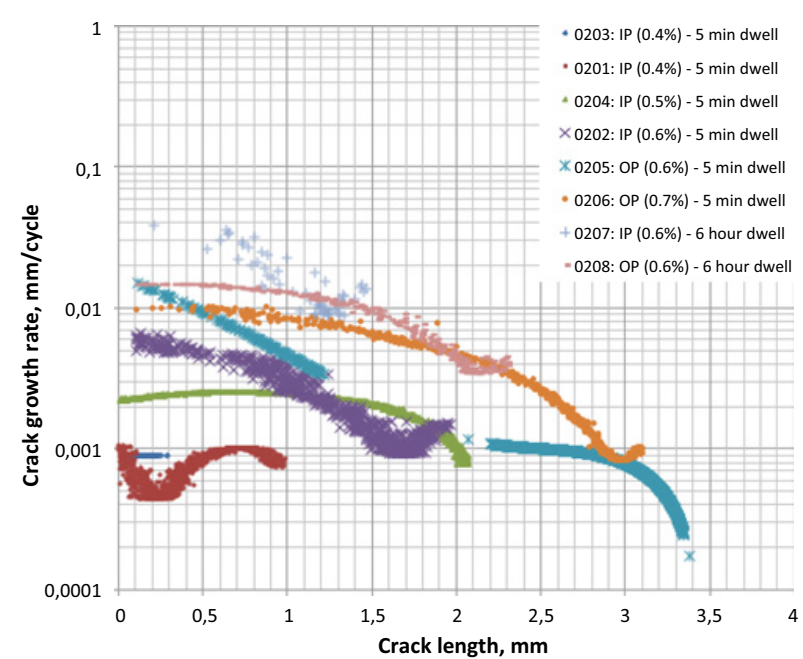

Figure 3. Crack growth rate as a function of crack length.

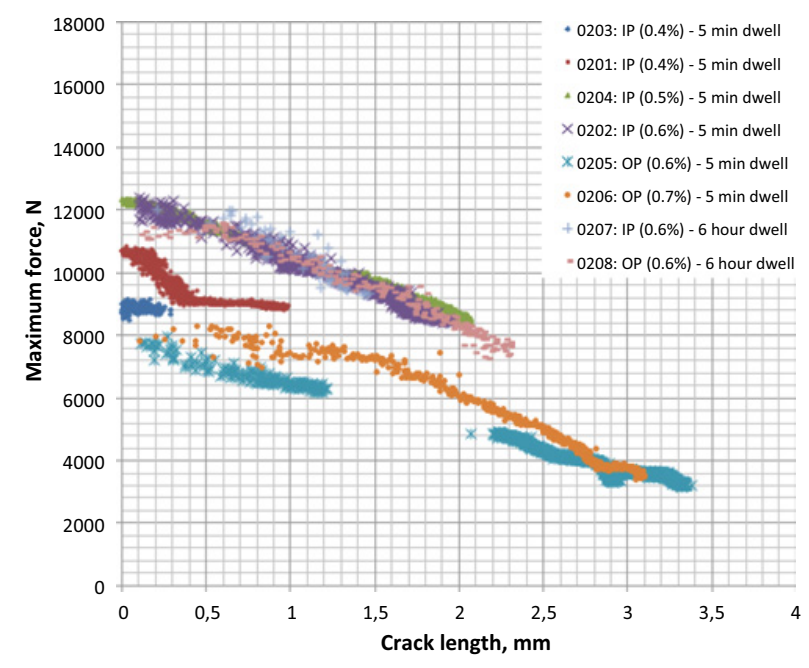

Figure 4. Maximum load as a function of crack length.

believed to be a consequence of the specimen geometry and the fact the tests were conducted in strain control.

In order to get quantitative data for crack propagation rates, a 4:th order polynomial was fitted to each curve in Fig. 2. The crack growth rates in each test were then evaluated as the slope of this polynomial and the results are plotted in Fig. 3. One can see that the crack growth rates (da/dN) increase with increasing $\Delta \varepsilon_{n o m}$ and that without dwell times, slightly higher crack growth rates were found for the OP-tests compared to IP-tests. Furthermore, it can be noticed that the introduction of a 6 hour dwell time leads to higher crack growth rates, especially for the IP-tests.

\subsection{Load response}

Since all tests in this study are conducted in displacement control (constant $\Delta \varepsilon_{n o m}$ ) the load response will change during the test as the crack becomes longer as illustrated in Fig. 4. As expected the maximum load generally increases with increasing $\Delta \varepsilon_{n o m}$. One can also see that the maximum load in general is higher in IP-tests compared to OP-tests. This is probably due to the difference in

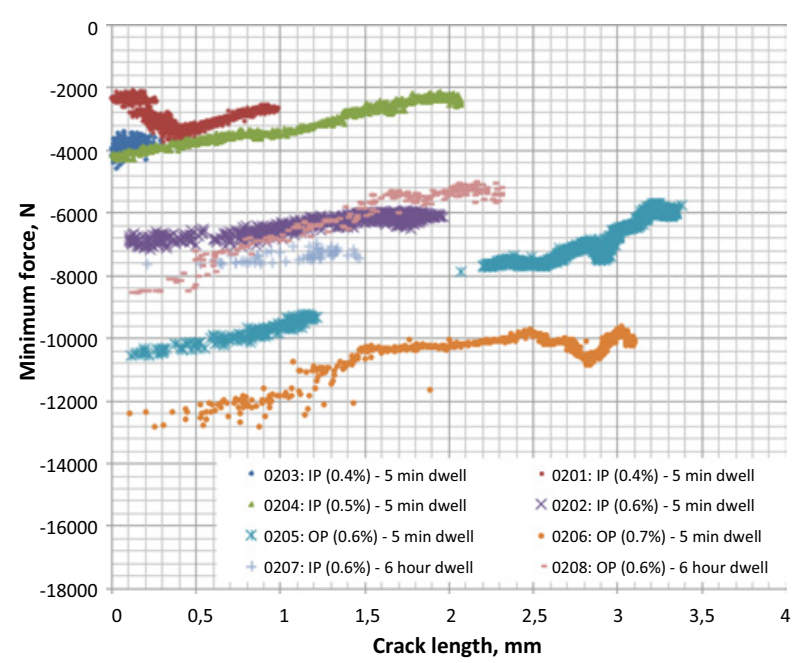

Figure 5. Minimum force as a function of crack length.

R-ratio between the two cycle types. While the IP-tests are conducted with $\mathrm{R}=0$ (going in tension as the temperature increases) the OP-tests are conducted with $\mathrm{R}=-\infty$ (going in compression as the temperature increases). One can also see that maximum load increases significantly when a dwell time of 6 hours is introduced in the OP-tests. However, no increase in maximum load can be observed when the dwell time is introduced in the IP-tests.

The minimum load as a function of crack length can be seen Fig. 5. As expected the compressive stress increases with increasing $\Delta \varepsilon_{\text {nom }}$. One can also see that the compressive stresses in general have a higher absolute value for the OP-tests compared to the IP-tests. Again this is probably due to the difference in R-ratio between the two cycle types. Furthermore, an influence of dwell times can mainly be seen for the OP-tests.

The reader should be reminded that the temperature at the maximum and minimum load differs between the different TMF-cycles. For the IP-TMF tests the maximum temperature occurs at the maximum load while the maximum temperature in the OP-TMF tests occurs at the minimum load. This difference will of course influence the direction in which the stresses are shifted due to creep relaxation effects. Anyhow even if this effect is taken into account the stress response with respect to dwell times is different between the two types of TMF-cycles when plotted as a function of crack length. One possible explanation for this is that the material responds differently to dwell times in the two cases.

For an IP-TMF test, the materials response to the dwell time is mainly an increase in the crack propagation rate (which then also leads to a reduction in the maximum stress, since the stress is performed in displacement control). Considering Fig. 4, this means that the dwell time shifts the curve both downwards but also to the right, giving no or limited net effect compared to tests with only a short dwell time.

For an OP-TMF test, the materials response to the dwell time is probably mainly a reduction of the compressive stresses at the maximum temperature due to creep relaxation. This leads to higher tensile stresses in the cold end of the TMF-cycle, giving slightly higher crack 


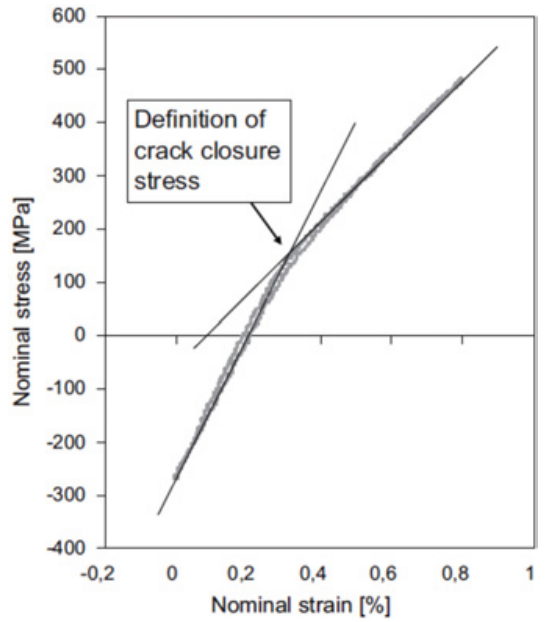

Figure 6. Definition of crack closure.

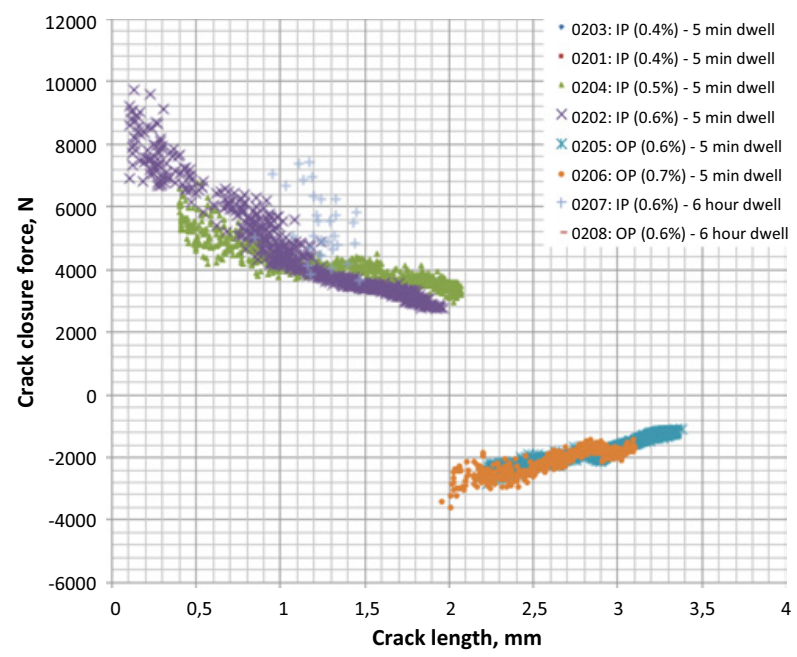

Figure 7. Crack closure force as a function of crack length.

growth rates for equivalent crack lengths. Thus, unlike the IP tests, the increased crack growth rates in the OP tests are just an effect of the stress response.

As a consequence, crack growth during the dwell time is only expected for the IP tests.

\subsection{Crack closure}

In addition to the stress response given in Fig. 4 and Fig. 5, an attempt has been made to estimate the crack closure levels during the different tests. The procedure for estimating the crack closure force is based on an evaluation where the stiffness of the specimen when the crack is open at maximum (tensile) load is compared to the stiffness when the crack is closed at minimum (compressive) load as illustrated in Fig. 6.

The results can be seen in Fig. 7. The crack closure level is always positive for the IP-tests while it is negative for the OP-tests. It should be noticed that the crack closure forces for the OP tests were only possible to evaluate for rather long cracks. The reason for this is that the slope of the curve in Fig. 6 is also influence by the elastic modulus (E) which changes with temperature during the TMF cycle. For the IP tests the slope is always lower on the tensile

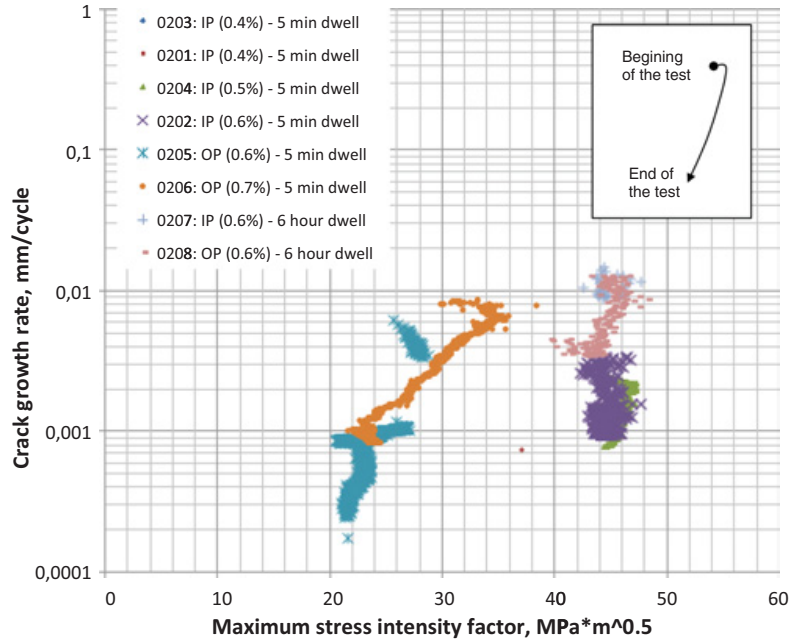

Figure 8. Crack growth rate as a function of the maximum stress intensity factor.

side where temperature is higher and the elastic modulus is lower. For OP tests, the opposite can be seen, i.e. the slope is higher on the tensile side due to lower temperature and higher elastic modulus but as the crack becomes longer, the stiffness becomes lower on the tensile side. During this transition the slopes are very similar and the evaluation of crack closure is not possible.

\subsection{Stress intensity factor}

Assuming that linear fracture mechanics is valid (which of course should be questioned at elevated temperature), the stress intensity factor is defined as:

$$
K_{I}=Y \cdot \sigma \sqrt{\pi a}
$$

where

$K_{I}$ is the stress intensity factor

$Y$ is the geometry factor

$a$ is the crack length.

For the specific specimen geometry used in this study a relationship between the stress intensity factor $K_{I}$, the crack length $a$ and the applied load $F$ has been established, see reference [1]. The relationship is based on 3D-FE simulations and linear elastic material behaviour using the Trinitas Software from Linköping University. The results can be seen in Fig. 8. A schematic illustration of how the curves in Fig. 8 evolve with time (crack length) can be found to the right in the figure. Generally the crack growth rate and the maximum stress intensity factor decreases as the test proceeds.

Even if the data in Fig. 8 provides a lot of scatter some general observations can be made. With short dwell times of 5 minutes, higher crack growth rates can be expected for OP-tests compared to IP-tests for equivalent $\mathrm{K}_{\text {Imax }}$ values. When a dwell time of 6 hour was introduced the crack propagation rate increased significantly in the IP-TMF test while it had very little effect in the OP-TMF test.

\subsection{Effective stress intensity factor range $\Delta K_{\text {eff }}$}

Using the data in Fig. 7 and the simple relationship given in Eq. (1) one can estimate the corresponding stress intensity 


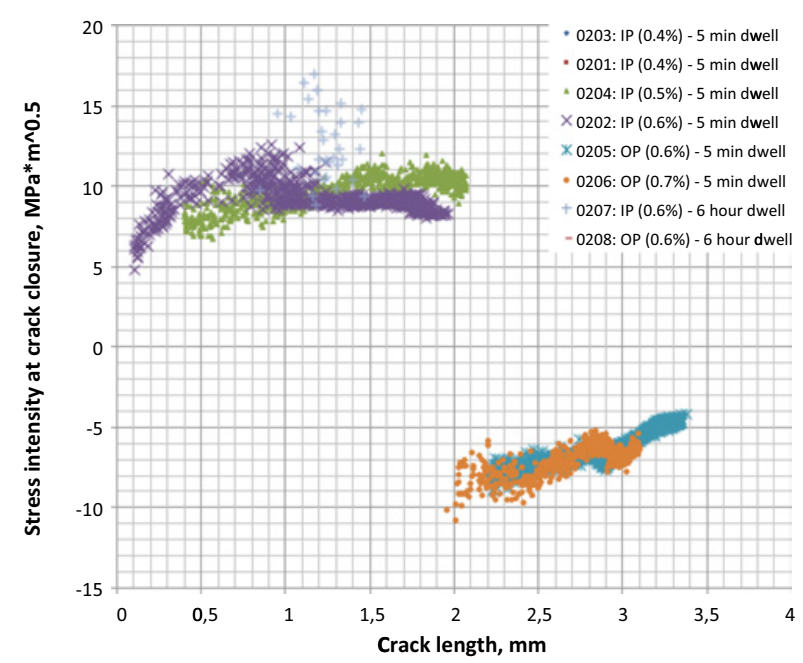

Figure 9. Stress intensity factor at crack closure versus crack length.

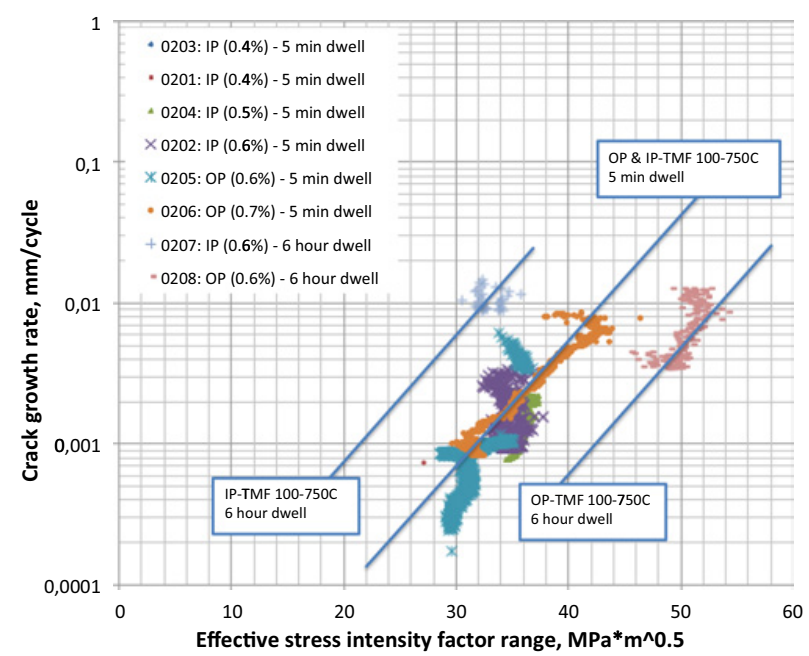

Figure 10. Crack growth rate $d a / d N$ as a function of the effective stress intensity factor range $\Delta K_{e f f}$.

factor for when crack closure occurs. The results are given in Fig. 9. It can be seen that the stress intensity factor at crack closure is rather constant for all tests with the same type of TMF cycle (IP or OP) and rather independent of crack length. As a rough estimate, it has been assumed that $K_{\text {closure }}$ is $10 \mathrm{MPa} \sqrt{ } \mathrm{m}$ for IP tests with 5 minutes dwell cycles, $12 \mathrm{MPa} \sqrt{ } \mathrm{m}$ for IP tests with 6 hour dwell cycles and $-7 \mathrm{MPa} \sqrt{ } \mathrm{m}$ for all $\mathrm{OP}$ tests.

An effective stress intensity factor range $\Delta K_{\text {eff }}$ can then be estimated according to Eq. (2).

$$
\Delta K_{\text {eff }}=K_{\text {Imax }}-K_{\text {closure }} .
$$

The dependency of $\Delta K_{e f f}$ on the crack growth rate $d a / d N$ can be seen in Fig. 10.

Even if there is some scatter in the data, the following conclusions can be made from Fig. 10; (1) for tests with 5 minutes dwell time, the IP and OP tests show roughly the same crack growth rate as a function of effective stress intensity range, (2) when a 6 hour dwell time is applied the crack growth rate increases by a factor of 10 for the IP

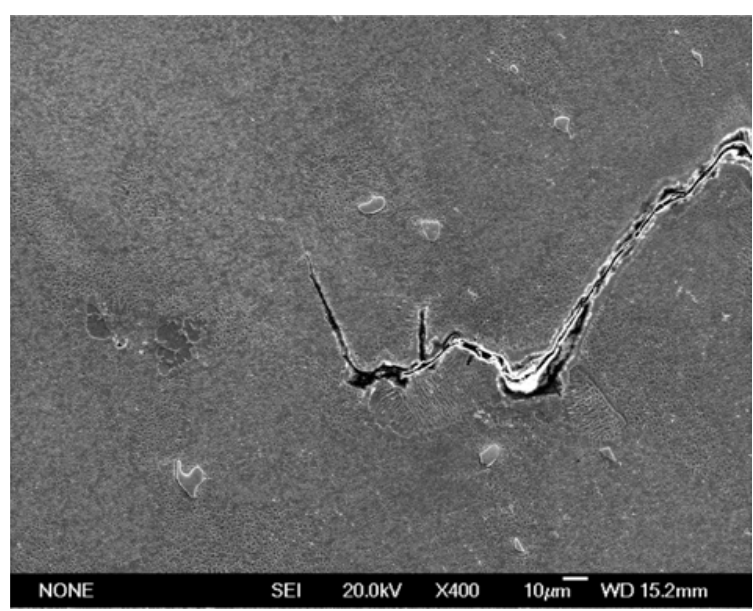

Figure 11. Cross section showing the appearance of the tip for the OP-TMF tests with 6 hour dwell time.

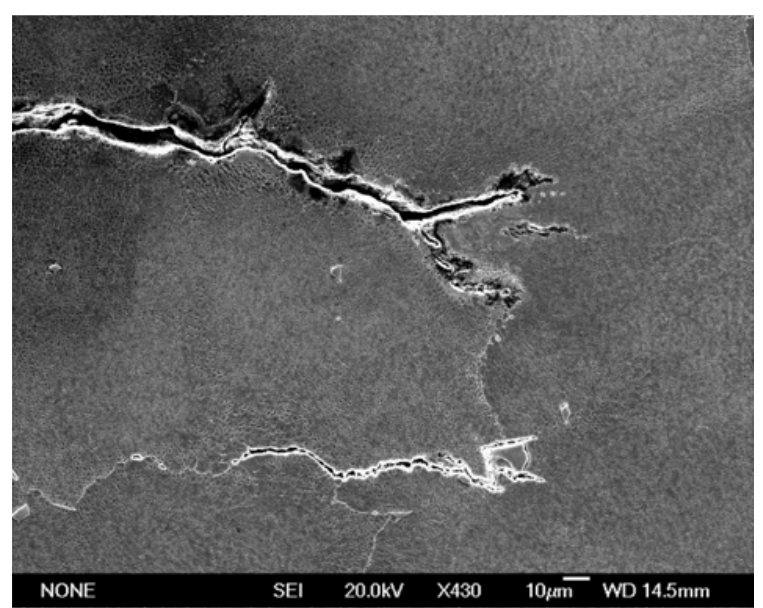

Figure 12. Cross section showing the appearance of the tip for the IP-TMF tests with 6 hour dwell time.

tests, while it is more or less unchanged or even decreases for the OP tests.

\subsection{Scanning electron microscopy}

Scanning electron microscopy has been used to reveal the typical appearance of the cracks with respect to the microstructure. In Fig. 11, the crack tip for the OPTMF tests with the 6 hour dwell time can be seen. The crack propagation occurs in a transgranular manner but significant crack deflection can often be seen. The deflections cause a serrated crack path and the distance between the serrations coincides very well with the load reversals.

In Fig. 12, the crack tip for the IP-TMF tests with the 6 hour dwell time can be seen. The crack propagation now seems to occur in an intergranular manner.

To further confirm the intergranular cracking behaviour during IP-TMF with 6 hour dwell time, orientation imaging microscopy has been carried out using EBSD. The results can be seen in Fig. 13. 


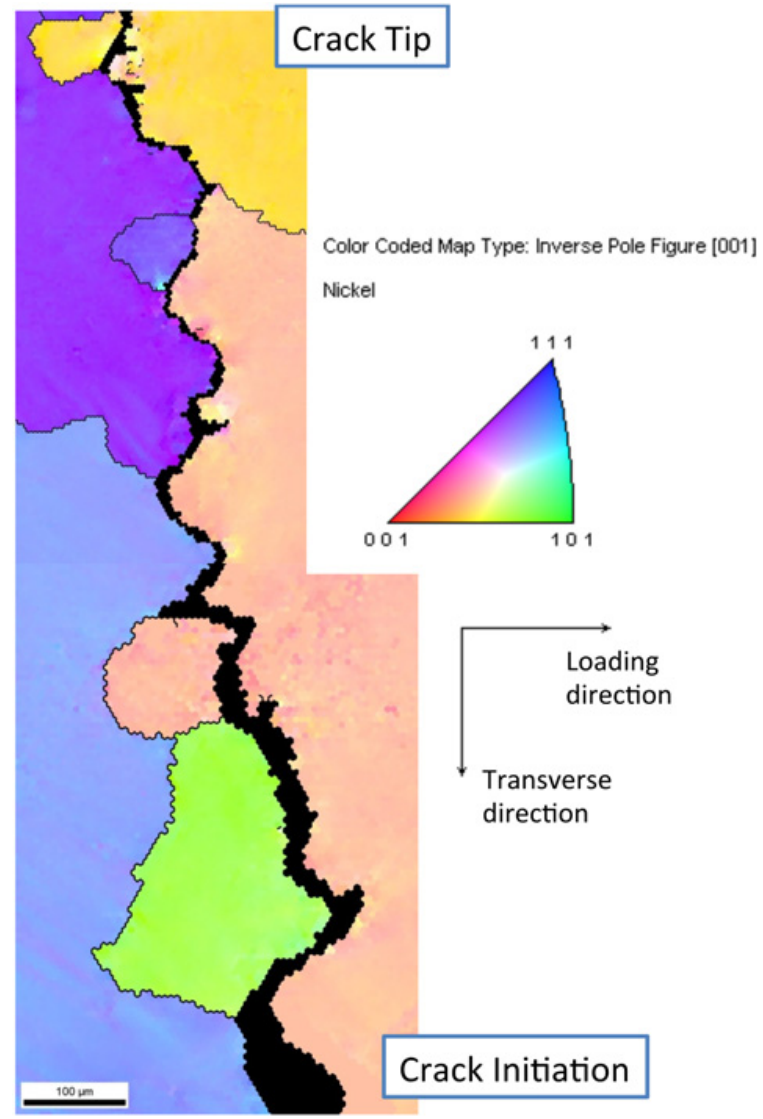

Figure 13. EBSD-map of grains surrounding the crack for the IP-TMF tests with 6 hour dwell time.

\section{Conclusions}

IP and OP TMF testing with 5 minute as well as 6-hour dwell time at the maximum temperature have been performed on the conventionally cast superalloy IN792. The main observations from the tests are:

- For tests with 5 minute dwell time, the IP and OP tests show roughly the same crack growth rate as a function of effective stress intensity factor range.

- When a 6 hour dwell time is applied, the crack growth rate increases by a factor of 10 for the IP tests, while it is more or less unchanged or even decreases for the OP tests.

- When a 6 hour dwell time is applied, the crack growth is transgranular in the OP tests while it is intergranular in the IP tests.

The work has been financially supported by Siemens Industrial Turbomachinery AB in Finspång, Sweden and the Swedish Energy Agency, via the Research Consortium of Materials Technology for Thermal Energy Processes, Grant No. KME-502.

\section{References}

[1] J. Moverare, D. Gustafsson, Mater. Sci. Eng. A 528, 8660 (2011)

[2] J. Kanesund, J. Moverare, S. Johansson, Mater. Sci. Eng. A 528, 4658 (2011)

[3] E.-G. Wagenhuber, V.B. Trindade, U. Krupp, The Role of Oxygen-Grain-Boundary Diffusion during Intercrystalline Oxidation and Intergranular Fatigue Crack Propagation in Alloy 718, in: E.A. L (Ed.). Proc. Int. Symp. Superalloys Var. Deriv. Pittsburgh, PA: (2005)

[4] D.A. Woodford, Energy Mater. Mater. Sci. Eng. Energy Syst. 1, 59 (2006)

[5] D. Gustafsson, J. Moverare, S. Johansson, K. Simonsson, M. Hörnqvist, T. Månsson, S. Sjöström, Int. J. Fatigue 33, 1461 (2011) 